\title{
Narcissistic Needs of the Self and Perceptions of Interpersonal Behavior
}

\author{
Steven B. Robbins and Philip Dupont \\ Virginia Commonwealth University
}

\begin{abstract}
A total of 78 mental health clients participating in therapy groups completed self-report measures corresponding to narcissistic personality defects derived from a self-psychology perspective and ratings of themselves on a checklist of interpersonal behavior. Also, pairs of group leaders were asked to rate clients on interpersonal behaviors. Results indicated a clear convergence of narcissistic needs and self-perceptions of interpersonal behaviors: Those with strong grandioseexhibitionistic needs viewed themselves as having both dominant and friendly behavior, whereas those with strong idealizing needs viewed themselves as being submissive and moderately hostile. Therapist ratings of interpersonal behaviors did not yield as many significant correlations with self-ratings of narcissistic needs: Those with grandiose-exhibitionistic needs were observed using dominant behavior and those with idealizing needs were observed using submissive behavior.
\end{abstract}

The premise of this study is that the narcissistic needs of the self should be related to interpersonal behavior. Kohut (1971, 1977, 1984) constructed a comprehensive developmental theory called psychology of the self, in which narcissistic needs refer to the natural striving toward self-expression or self-promotion that is central to all personality development. From this perspective, self-expression and narcissism are parts of the same developmental process, in which the self increasingly relies on internal rather than external sources both to maintain a sense of permanence and well-being and to develop native talents and skills. Pathological narcissism is a result of faulty self-development and results in the maladaptive use of interpersonal relations to promote self-expression.

Kohut (1971) theorized that the self is the initiating center of the personality and reflects basic narcissistic or self-expressive needs contained in two lines of development, the grandiose-exhibitionistic and the idealizing (a third line, the alter ego, was tentatively incorporated into the theory (Kohut, 1984) just prior to Kohut's death and is not used in this article). In the young child, the needs of the self are met through important others, who provide external sources of support and encouragement. Through phase-appropriate and nontraumatic lapses in parental empathy, the child begins to internally regulate a sense of stability and security and to use his or her native talents and skills. More specifically, in the grandiose-exhibitionistic sector, the immature self uses the admiration and approval of others to provide a sense of selfworth, whereas in the mature self, self-esteem and ambition are internally regulated. In the idealizing sector, the immature

This project was funded in part by a biomedical grant-in-aid from Virginia Commonwealth University.

We thank Donald J. Kiesler for assistance with the design and interpretation of this study and Stephen Herrick for heip with the calculations of the intraclass correlation coefficients.

Correspondence concerning this article should be addressed to Steven B. Robbins, Department of Psychology, Box 2018, Virginia Commonwealth University, Richmond, Virginia 23284-2018. self maintains a sense of security and direction through powerfully perceived others, whereas in the mature self, a system of ideals and values is in place.

How the social world is intrapsychically experienced (based on what Kohut, 1984, called self-self-object relations, or the self experiencing its own representation of important others) is contingent on the narcissistic needs of the bipolar lines of the self and available social relations. In other words, disturbances in the grandiose-exhibitionistic line will result in aggrandizing and dominant behaviors and disturbances in the idealizing line will result in social hypersensitivity and withdrawal. Thus, a common link between seemingly contradictory or independent sets of behavior is the inability to soothe or regulate the self and the reliance on the external world to provide a basic sense of self-worth (e.g., healthy narcissism defined as mature ambition and goals).

Robbins and Patton (1985) constructed the Superiority Scale and the Goal Instability Scale to measure defects in the grandiose-exhibitionistic and idealizing lines of the self, respectively. To test the divergent and convergent validity of the Superiority Scale and the Goal Instability Scale, Robbins (1989) compared them with both personality pattern and clinical syndrome scales from the Millon Clinical Multiaxial Inventory (MCMI; Millon, 1983) and with therapist ratings of personality traits and symptom patterns in 91 clients from a cross-section of outpatient and inpatient mental health settings. The Superiority Scale was related to a pattern of social gregariousness, interpersonal exploitation, and impulsivity and the Goal Instability Scale was related to a pattern of social withdrawal, depression, and lack of ambition and goals.

Robbins (1989) used a mental health population to test the hypothesis that superiority and goal instability represent maladaptive forms of narcissism. Although Robbins found that divergent types of mental health clients emerge on the basis of the location of the self defect, these findings were based on limited social interactions without a clearly defined social context (such as a therapy group or residential setting). By choosing an interpersonal context in which social behaviors are encouraged, one can test the relationship between self- 
perceptions of the narcissistic needs of the self and both self and other perceptions of interpersonal behavior.

Furthermore, the needs of the self have not been examined with clearly formulated indexes of interpersonal behavior (e.g., Kiesler, 1983; Wiggins, 1979). Clear relationships should exist between self-perceptions of the narcissistic needs of the self and different patterns of interpersonal behavior because of the importance of social relations to buttress or support a self that cannot internally sustain a sense of well-being. The contradictory qualities of narcissistic behaviors point to the increasing difficulties of relying solely on the descriptive nosology provided within the Diagnostic and Statistical Manual of Mental Disorders, 3rd ed., rev. (DSM-III-R; American Psychiatric Association, 1987) for Axis II personality disorders. As Millon (1981) has argued, we must understand the underlying dimensions that link a complex amalgam of interpersonal behaviors and attitudes.

Interpersonal theorists in particular are now developing models to differentiate and link various personality disorders (e.g., Kiesler, 1986a, 1986b; Pincus \& Wiggins, 1990; Sim \& Romney, 1990). These theorists are using what is called the interpersonal circumplex model of interpersonal behavior to describe personality disorders. This model (see Orford, 1986, or Wiggins, 1979 , for reviews) contains the premise that behavior can be categorized along two basic dimensions: the affiliative, ranging from hostile to friendly, and the control, ranging from dominant to submissive. A circle is formed in which the control dimension is placed on the horizontal axis and the affiliation dimension is placed on the vertical axis. A circumplex model is constructed that can be conceptualized along either axis or any quadrant, octant, or one of 16 segment dimensions, representing varying proportions of control and affiliation.

To measure each axis, Kiesler and Goldston (1987) developed the Checklist of Interpersonal Transactions (CLOIT), which contains a checklist of 96 behaviors. The CLOIT can be administered either as a self-report or as a transactant rating. Kiesler and his colleagues (Kiesler, 1986a, 1986b; Kiesler, Van Denburg, Sikes-Nova, Larus, \& Goldston, 1990) theorized that each personality disorder will be represented by varying degrees of interpersonal behaviors on the circumplex model. They classified behaviors associated with the $D S M-I I I-R$ (American Psychiatric Association, 1987) narcissistic personality-corresponding to the characteristic measured by the Superiority Scale or to a defect in the grandiose self-as being histrionic and rigidly autonomous, reflected by high dominance and affiliation. In two separate studies of personality disorders and interpersonal behavior (Kiesler et al., 1990; Pincus \& Wiggins, 1990), dominant-assured and exhibitionistic-sociable octants were found to be most representative of this type.

With regard to defects in the idealizing line of the self, no specific $D S M-I I I-R$ Axis II category exists. Robbins (1989) found that a defect in this line is associated with social withdrawal, hypersensitivity, and reliance on others, conceptually similar to the contact-shunning type of personality (Kohut \& Wolf, 1978; Robbins, 1989). Robbins argued that this pattern was observed in the avoidant, schizoid, and borderline $D S M-I I I-R$ Axis II disorders (American Psychi- atric Association, 1987). Interestingly, Kiesler et al. (1990) found a similar mixed interpersonal pattern of behavior when examining eight personality disorder interpersonal behavior profiles. They found that the Schizoid and Avoidant disorders had shared characteristics, encompassing the submissive-unassured end of the control axis and the hostile end of the affiliation axis.

Thus, the goal of this study is to draw on two different theoretical perspectives to link self and interpersonal constructs. This study (a) attempts to determine whether patterns of interpersonal behavior predicted by Kohut's $(1971,1977)$ theory emerge in relation to the expressed needs contained in the grandiose and idealizing sectors of the self as measured by the Goal Instability Scale and the Superiority Scale (Robbins \& Patton, 1985) and (b) attempts to obtain both self-report and therapist perceptions of interpersonal behavior. We selected outpatient therapy group members as subjects to enable us to observe behaviors within an ongoing interactive context; to sample a wide variety of personality characteristics, interpersonal styles, and levels of psychopathology; and to increase observer reliability by using pairs of group leaders.

\section{Method}

\section{Subjects}

Clients were recruited from 12 outpatient therapy groups conducted at mental health, counseling center, and Veteran's Administration settings. These settings contained established therapy group programs for which both staff and interns were selected because of strong therapy group training/experience. Clients were chosen who had at least 2 months but no more than 1 year of cumulative participation within the groups, which were stable, ongoing groups that had been running from 6 months to 3 years. These groups were chosen because they represented a cross-section capable of interacting with other members and the group leaders. We purposefully chose groups that did not contain clients socially impaired by either acute or chronic schizophrenia.

A total of 78 therapy group members of a possible 111 were accepted in the study. Of the 33 nonparticipants, 12 clients with histories of schizophrenia, organic brain disorders, or acute alcoholism were excluded from the study. Another 12 did not complete full packets of information, and 9 participants did not agree to participate. Time in treatment for the participants averaged 5.8 months. Of the 78 subjects, $70 \%$ were male and the mean age was 25.9 years ( $S D=$ 10.8 years). Ninety-four percent were White and $5 \%$ were Black, and $1.9 \%$ were Asian. With regard to marital status, $80 \%$ were single, $10 \%$ were married, and $10 \%$ were divorced or widowed. Educational background was relatively high, with $78 \%$ having completed some college, $18 \%$ being college graduates, and $6 \%$ having obtained high school degrees.

To confirm the range of personality disturbance required to test broad patterns of relationships between self and interpersonal constructs, diagnoses based on the $D S M-I I I-R$ were obtained through the consensus of intake worker and group leaders. In this way a high level of agreement $(96 \%)$ was reached. Client diagnoses included $47 \%$ with a primary Axis I diagnosis, $18 \%$ with a primary Axis II diagnosis, $30 \%$ with a dual diagnosis, and $3 \%$ with no diagnosis given. Axis I diagnoses were broken down into adjustment disorders (24\%), family/ academic/interpersonal problems (26\%), depression (14\%), dysthymia $(10 \%)$, anxiety $(12 \%)$, substance abuse related problems $(8 \%)$, eating disorder $(4 \%)$, and other $(2 \%)$. Axis II diagnoses included 
avoidant (28\%); dependent (28\%); narcissistic (16\%); passive-aggressive $(12 \%)$; and others, including mixed, borderline, and compulsive $(16 \%)$.

\section{Therapists}

A total of 10 therapist dyads ( $N=20$ therapists; 2 of the therapist dyads rated 2 groups and the other 8 dyads rated 1 group to equal 12 total groups) participated, with an average across all therapists of 5.6 years group therapy experience $(S D=5.3$ years, $M d n=5.0$ years, range $=14$ months to 20 years). Therapists were a cross-section of psychologists $(n=8)$, social workers $(n=4)$, doctoral psychology interns $(n=6)$, and psychiatric residents $(n=2)$. A total of 12 women and 8 men participated. Each therapy group was conducted by a team of two therapists; each patient in the present study was independently rated by each of his or her two therapists.

\section{Self-Scales}

Superiority Scale. The 10-item self-report Superiority Scale (Robbins \& Patton, 1985) was constructed to correspond to the grandiose sector of the self. The 6-point Likert items include the wish to be admired, unrealistic appraisal of self, and exhibitionism. The greater the agreement with the items, the higher is the subject's superiority. Test-retest reliability of .80 , internal consistency of .76, and factorial stability demonstrate the test's strong psychometric qualities. A number of studies (e.g., Robbins, 1989; Robbins \& Patton, 1985; Watson, McKinney, Hawkins, \& Morris, 1988) support the Superiority Scale's convergent and divergent validity as a measure of narcissistic behaviors associated with the grandiose-exhibitionistic line of development, including a high correspondence with other measures of narcissism (e.g., Narcissistic Personality Inventory; Emmons, 1984).

Goal Instability Scale. The 10-item self-report Goal Instability Scale (Robbins \& Patton, 1985) was constructed to correspond to the idealizing sector of the self. The 6-point Likert items include the inability to set goals and direction, confusion about self, and an inability to finish projects. High agreement with test items represents greater goal instability or difficulty. Test-retest reliability of .76 , internal consistency of .77, and factorial stability are indicators of its strong psychometric qualities. Goal instability has been found to be a more generalized measure of difficulty (Robbins, 1989) than originally hypothesized but has strong convergent, divergent, and construct validity (e.g., Robbins, Payne, \& Chartrand, 1990; Robbins \& Tucker, 1986; Watson et al., 1988). In any case, Watson et al. (1988) found the Goal Instability Scale to correspond to maladaptive measures of narcissism, including psychic distress and poor empathic regard.

Checklist of Interpersonal Transactions-Revised. For the present study, the rationally derived 96 -item checklist of interpersonal behavior constituting the CLOIT was used for both self-report and transactant ratings. Items on the two versions are identical except for the respective stems: "When with others I ..." or "When in my company, this person ..." For the purposes of the present study, Control and Affiliation axes scores were calculated on the basis of vector values derived from the 16 segment scales, with each score ranging from -45.24 to +45.25 (for discussion see Kiesler \& Goldston, 1988; Mahalik, Hill, O'Grady, \& Thompson, in press). Negative scores indicate submission or hostility, and positive scores indicate dominance or friendliness on the Control and Affiliation scales, respectively.

The CLOIT is a face valid measure of interpersonal behavior, with both convergent and divergent validity (Kiesler \& Goldston, 1988; Kiesler et al., 1990; Kiesler \& Watkins, 1989). Weinstock-Savoy (1986) reported moderate to high concurrent validity correlations
(.46 to .80$)$ between comparable octant scores on the CLOIT and the Wiggins Interpersonal Adjective Scales (Wiggins, 1979; Wiggins, Trapnell, \& Phillips, 1988). Weinstock-Savoy (1986) also reported three estimates of reliability all indicating moderate to low levels of interjudge agreement for octant scores: First, a regression analysis produced correlations $(r \mathrm{~s})$ ranging from .56 to $.83(M=.69)$. Second, correlations of individual rater scores for a given octant with the mean octant scores of all raters who viewed a particular audiotape ranged from .70 to $.93(M=.82)$. Third, internal consistency coefficients average .63 , with a range of .43 to .81 . Mahalik et al. (in press) recommended use of the axis scores to avoid problems with rater reliability.

\section{Rater Reliability}

For the purposes of this study, reliability coefficients between the pairs of therapist/raters were calculated with an intraclass correlation coefficient. The procedures by Shrout and Fleiss (1979) for a Case 1 study (each target is rated by a different set of $K$ judges randomly selected from a large population of judges) were used to calculate the intraclass correlations for the axis scores, with Control intraclass $r=$ .75 and Affiliation intraclass $r=.80$.

\section{Procedure}

All subjects were contacted in person by the experimenter or group leaders. Subjects returned a packet of materials to the experimenter and received a $\$ 10$ payment as compensation for their time. Therapist/raters were notified that a member of their group had participated and were asked to complete the CLOIT. They also received $\$ 10$. Only groups in which both facilitators agreed to participate were selected to ensure that pairs of ratings would be gathered.

\section{Results}

Presented in Table 1 are the scale intercorrelations, means, and standard deviations for all variables. Superiority Scale and Goal Instability Scale mean scores were comparable to those of other mental health populations (cf. Robbins, 1989), and as expected the scales operated independently of each other $(r=-.15)$. Mean CLOIT therapist ratings of clients on the Control axis reflected submissive behavior $(M=-2.26)$ and mean ratings on the Affiliation axis reflected friendly behavior $(M=.62)$. Self-report ratings of Affiliation were friendly, with overall positive scores $(M=5.21)$. Mean selfratings on the Control axis $(M=-1.97)$ were submissive. Superiority was significantly correlated to the Control and Affiliation dimensions, whereas Goal Instability was only negatively correlated with Control. Interestingly, therapist rating of Affiliation and self-report Affiliation were not correlated $(r=.12)$.

Two canonical correlation analyses (Cohen \& Cohen, 1983) were performed. The first canonical analysis was conducted between the set of self-scales (Goal Instability Scale and Superiority Scale) and the transactant (therapist-rated) CLOIT axis scales: Affiliation and Control. One significant canonical correlation $(p<.01)$ was identified, with $R_{\mathrm{c}}=.45\left(R_{\mathrm{c}}{ }^{2}=.20\right)$. The correlations of variables in each set with the canonical variate are summarized in Table 2. According to Cohen and Cohen, only correlations over .30 are interpreted. As can be seen, the Goal Instability Scale has a high negative correlation 
Table 1

Intercorrelations, Means, and Standard Deviations on Therapist and Self-Report Variables

\begin{tabular}{lrrrrrrrr}
\hline \multicolumn{1}{c}{ Variable } & \multicolumn{1}{c}{$M$} & $S D$ & 1 & 2 & 3 & 4 & 5 & 6 \\
\hline 1. Rater affiliation & 0.62 & 3.68 & - & & & & & \\
2. Rater control & -2.26 & 3.86 & .11 & - & & & \\
3. Affiliation & 5.21 & 4.76 & .12 & .05 & - & & \\
4. Control & -1.97 & 5.04 & .12 & $.58^{* *}$ & .17 & - & & \\
5. Goal instability & 34.99 & 8.75 & .00 & $-.40^{* *}$ & .12 & $-.45^{* *}$ & - & - \\
6. Superiority & 33.18 & 7.22 & .01 & $.25^{*}$ & $.28^{*}$ & $.40^{* *}$ & -.15 & -
\end{tabular}

Note. $N=78$. Measures of rater affiliation, rater control, affiliation, and control are from the Checklist of Interpersonal Transactions-Revised. The measure of goal instability is from the Goal Instability Scale, and the measure of superiority is from the Superiority Scale. Rater affiliation and rater control scores represent the average across raters. Positive mean values designate the friendly side of the affiliation and the dominant side of the control axis; negative mean values designate hostility and submission, respectively.

$* p<.05 . * * p<.01$.

with the canonical variate, whereas the Superiority Scale has a moderate positive correlation. In turn, the Control (dominant behavior) axis score was highly correlated with the canonical variate. Contrary to hypothesis, the Affiliation dimension was not correlated with the canonical variate.

Turning to the canonical correlation analysis between the self-scales and the client self-report CLOIT scale, we found that one significant canonical correlation was identified ( $p<$ $.01)$, with $R_{\mathrm{c}}=.61\left(R_{\mathrm{c}}{ }^{2}=.36\right)$. The correlations of variables in each set with the canonical variate are summarized in Table 3. As can be seen, Goal Instability and Superiority are both moderately to highly correlated with the canonical variate, but in opposite directions. Control was highly correlated with the canonical variate, whereas Affiliation was moderately correlated with the canonical variate. These results suggest that high superiority is related to increased dominance and outgoing/friendly interpersonal behaviors, whereas low goal instability is related to submissive and moderately hostile/ detached interpersonal behaviors.

\section{Discussion}

This study was based on the belief that broad patterns of interpersonal behavior within a mental health client population would relate to disturbances within the grandiose-exhi-

Table 2

Canonical Analysis of the Self-Scales With Therapist Ratings of Interpersonal Behavior

\begin{tabular}{cc}
\hline Measure & $\begin{array}{c}\text { First canonical } \\
\text { variate }\end{array}$ \\
\hline Self-scales (Set 1) & \\
Goal Instability & -.83 \\
Superiority & .55 \\
Ratings of interpersonal behavior & \\
(Set 2) & .02 \\
Affiliation & .99 \\
Control & \\
\hline
\end{tabular}

Note. $N=78$. All values except .02 (Affiliation) were used for interpretation. Axis scale scores are reported for the ratings of interpersonal behavior. The self-scales were reverse keyed from the original (Robbins \& Patton, 1985) so that higher scores represent greater goal instability and superiority. bitionistic or idealizing trends of the self (Kohut, 1984; Patton \& Robbins, 1982). The canonical correlations data-analytic strategy relies on a spectrum approach that attempts to identify underlying dimensions from a diverse range of behaviors rather than focusing on specific diagnostic categories or individual client cases. Moreover, this study placed a premium on perceptions of interpersonal behavior based on ongoing interactions between participants. This strategy is consistent with both self theorists' (Robbins, 1989) and interpersonal theorists' (cf. Kiesler, 1986a; Pincus \& Wiggins, 1990) argument that rigid maladaptive interpersonal patterns of interaction with significant others create an interpersonal field that perpetuates disturbances in the self.

Interestingly, self-ratings of interpersonal behavior more consistently depicted the expected relationships between the narcissistic needs of the self and interpersonal behavior: Grandiose-exhibitionistic needs were related to a strong dominant style with a tendency toward friendliness, whereas idealizing needs were related to a submissive and moderately hostile style. These findings are congruent with the observations of Kohut (1971) in which the transference reactions of analysands were described with intense mirroring and idealizing needs. Kohut observed that clients with disturbances in the grandiose self use social relations as a mirror for their own self-aggrandizement to buttress a fragile self. Those with disturbances in the idealizing self seek out the approval and security of others, while at the same time anticipating rejection.

Only partial confirmation of these two patterns was obtained between the narcissistic needs of the self and therapistrated interpersonal behaviors. As expected, grandiose-exhibitionistic and idealizing needs were related to the dominant and submissive ends of the Control axis, respectively. Therapist ratings on Affiliation were not related to self-perceptions of narcissistic needs. It is unclear why therapists did not distinguish therapy group clients on the Affiliation dimension. Mahalik et al. (in press) found that the Affiliation axis was difficult for judges to rate objectively. They suggested that more inference is required to rate the friendly-hostile spectrum because of less observable behavior than on the dominance-submission dimension, with the resulting need to attribute internal states to therapy participants. 
Table 3

Canonical Analysis of the Self-Scales With Self-Ratings of Interpersonal Behavior

\begin{tabular}{cc}
\multicolumn{1}{c}{ Measure } & $\begin{array}{c}\text { First canonical } \\
\text { variate }\end{array}$ \\
\hline $\begin{array}{l}\text { Self-scales (Set 1) } \\
\text { Goal Instability }\end{array}$ & -.72 \\
Superiority & .83 \\
Self-ratings of interpersonal & \\
$\quad$ behavior (Set 2) & \\
Affiliation & .47 \\
Control & .93 \\
\hline
\end{tabular}

Note. $N=78$. All values shown were used for interpretation. Axis scale scores are reported for the self-ratings of interpersonal behavior. The self-scales were reverse keyed from the original (Robbins \& Patton, 1985) so that higher scores represent greater goal instability and superiority.

Use of the axis scores on the CLOIT also reduced finer grained analyses of interpersonal behaviors that may have yielded different results on the Affiliation dimension. Because of rater reliability difficulties with the CLOIT (see Mahalik et al., in press, for a review), we used the broadest estimates of interpersonal behaviors in the present study to improve the reliability of the instrument. At a minimum, greater control of therapist sources of rater bias is necessary to improve interrater reliability. For example, a wide range of experience levels were found within the therapy group leaders ( 1 year to 20 years, $S D=5.3$ years). Therapy group leaders also may have been engaged with the clients in ways that increased rater bias and decreased interrater reliability. Use of multiple raters who are not actively participating in the therapy group process is another strategy that (a) may allow for the derivation of reliable octant or segment scores based on the CLOIT and (b) may provide a different type of observer information.

Differences between self and other ratings of interpersonal behavior point to some of the most intriguing findings of the study. Those persons with grandiose-exhibitionistic needs viewed themselves as being affiliative, whereas therapy group leaders did not observe affiliation behaviors. In turn, those individuals with idealizing needs viewed themselves as engaging in interpersonal behaviors that were moderately hostile. These findings suggest a discrepancy between client and therapist perceptions that may reflect difficulties with realistic selfappraisal (cf. Patton \& Robbins, 1982; Pincus \& Wiggins, 1990). Idealizing clients in particular may tend to internalize greater inhibited and detached responses than were being observed. This finding provides insight into the hypersensitivity and fearfulness typically associated with persons experiencing defects in the idealizing self (Kohut \& Wolf, 1978; Patton \& Robbins, 1982).

It is important to reiterate that only one significant canonical variate emerged when we examined the self scales and interpersonal behavior. This canonical variate was bipolar, with the grandiose and idealizing needs of the self operating in opposition to each other when compared to interpersonal behavior patterns. This finding is contrary to the results of Robbins's (1989) study of mental health clients, in which the self-scales were compared with noninterpersonal indexes of behavior and in which two separate canonical variates emerged, each corresponding to either the Superiority Scale or the Goal Instability Scale. One explanation for the current findings can be found in the nature of the circumplex model. The axis scores that emerged in relation to both the grandioseexhibitionistic and idealizing needs of the self fell at bipolar opposite ends of an interpersonal dimension ranging from friendly-dominance (dominant-assured, exhibitionistic-sociable) to hostile-submission (submissive-unassured). Hence, the scores represent bipolar opposite sets of interpersonal behaviors.

From a self-psychological view, the seemingly divergent mirroring and merging transference reactions (corresponding to defects in the grandiose-exhibitionistic and idealizing sides, respectively) reflect a core problem related to a fragile selfsystem. As Patton and Robbins (1982) have detailed, whereas the compensatory and adaptive strategies used by persons vary as a function of the location of the defect in the self, the underlying or core issue is an inability to regulate self-esteem and tension gradients within the self. This notion of "two sides of the same coin" helps to connect the empirically derived multiple factors Mullins and Kopelman (1988) found when analyzing measures of narcissism.

In any case, this study was a first attempt at clarifying the ways in which faulty interpersonal patterns are associated with self-disorders (Kohut \& Wolf, 1978). Research must begin to integrate interpersonal and self-psychological perspectives on the root causes of breakdowns in social relations. Our theoretical position is that regardless of the specific style of maladaptive interpersonal responses (e.g., strong or weak dominance-affiliation responses), they are a result of a vulnerable self that attempts to bolster itself by using the social world as a buffer. A vicious cycle occurs, in which faulty interpersonal behavior results in a breakdown of interpersonal relations and the concomitant reinforcement of these same faulty interpersonal strategies to bolster a fragile sense of self.

Future research must begin to understand the mechanisms involved in maladaptive interpersonal behavior. Those clients presenting rigid and faulty interpersonal responses (a) may have a great discrepancy between self and other perceptions of their interpersonal behaviors, whether overestimating or underestimating disturbances; (b) may be unable to process interpersonal feedback in such a way as to minimize assaults to their self-esteem and shame responses; and (c) may need to understand that their syndromatic style of behavior represents an absence of specific internal resources, such as selfesteem regulation, ambition and goals, or empathic regard.

This study relied on a relatively small sample for multivariate statistics. A replication of this study would answer questions about both the stability and generalizability of findings. The outpatient mental health and counseling center therapy groups used in this study were composed of persons able to engage in social relations over a period of time. Use of more severely disturbed clients may have resulted in a different pattern of correlations. Although the study was designed to obtain a diversity in diagnostic types, the general level of functioning of clients was clearly high. The careful identification and assessment of narcissistic personality types through an interpersonal perspective would yield more in-depth infor- 
mation about the exact relationship between internal processes, such as need states and interpersonal behavior (see Emmons, 1989, for discussion). Finally, this study examined the broad patterns of relationships between self and interpersonal behaviors. The question of whether people are narcissistic because of faulty interpersonal patterns or have faulty interpersonal patterns because of narcissistic issues has not been answered.

\section{References}

American Psychiatric Association (1987). Diagnostic and statistical manual of mental disorders (3rd ed., rev.). Washington, DC: Author.

Cohen, J., \& Cohen, P. (1983). Applied multiple regression/correlation analysis for the behavioral sciences. Hillsdale, NJ: Erlbaum.

Emmons, R. (1984). Factor analysis and construct validity of the Narcissistic Personality Inventory. Journal of Personality Assessment, 48, 291-300.

Emmons, R. (1989). Exploring the relations between motives and traits: The case of narcissism. In D. Buss \& N. Cantor (Eds.), Personality psychology: Recent trends and emerging directions (pp. 32-44). New York: Springer-Verlag.

Kiesler, D. (1983). The 1982 interpersonal circle: A taxonomy for complementarity in human transactions. Psychological Review, 90 , 185-214.

Kiesler, D. (1986a). Interpersonal methods of diagnosis and treatment. In J. D. Cavenar (Ed.), Psychiatry (Vol. 1, pp. 1-23). Philadelphia: Lippincott.

Kiesler, D. (1986b). The interpersonal circle: An analysis of DSMIII personality disorders. In T. Millon \& G. Klerman (Eds.), Contemporary directions in psychopathology: Towards the DSM-IV (pp. 571-597). New York: Guilford Press.

Kiesler, D., \& Goldston, C. (1987). Checklist of Interpersonal Transactions-Checklist of Psychotherapy Transactions (Rev.). Unpublished manual, Virginia Commonwealth University, Richmond.

Kiesler, D. J., \& Goldston, C. S. ( 1988). Client-therapist complementarity: An analysis of the Gloria films. Journal of Counseling Psychology, 35, 127-133.

Kiesler, D., Van Denburg, T., Sikes-Nova, V., Larus, J., \& Goldston, C. (1990). Interpersonal behavior profiles of eight cases of DSMIII personality disorders. Journal of Clinical Psychology, 46, 440453.

Kiesler, D., \& Watkins, L. (1989). Interpersonal complementarity in psychotherapy. Psychotherapy, 26, 183-194.

Kohut, H. (1971). The analysis of the self. Madison, CT: International Universities Press.

Kohut, H. (1977). The restoration of the self. Madison, CT: International Universities Press.

Kohut, H. (1984). How does analysis cure? Chicago: University of Chicago Press.
Kohut, H., \& Wolf, R. (1978). The disorders of the self and their treatment: An outline. International Journal of Psychoanalysis, 59, 413-425.

Mahalik, J., Hill, C., O’Grady, K., \& Thompson, B. (in press). Rater characteristics influencing rating on the Checklist of Psychotherapy Transactions-Revised. Psychotherapy Research.

Millon, T. (1981). Disorders of Personality: DSM-III, Axis II. New York: Wiley.

Millon, T. (1983). Millon Clinical Multiaxial Inventory Manual (3rd ed.). Minneapolis: Interpretive Scoring System.

Mullins, L., \& Kopelman, R. (1988). Toward an assessment of the construct validity of four measures of narcissism. Journal of Per. sonality Assessment, 52, 610-625.

Orford, J. (1986). The rules of interpersonal complementarity: Does hostility beget hostility and dominance, submission? Psychological Review, 93, 365-377.

Patton, M., \& Robbins, S. (1982). Kohut's self-psychology as a model for college student counseling. Professional Psychology, 13, 876888.

Pincus, A., \& Wiggins, J. (1990). Interpersonal problems and conceptions of personality disorders. Journal of Personality Disorders, 4, 342-352.

Robbins, S. (1989). Validity of the Superiority and Goal Instability scales as measures of defects in the self. Journal of Personality Assessment, 53, 122-132.

Robbins, S. B., \& Patton, M. J. (1985). Self-psychology and career development: Construction of the Superiority and Goal Instability scales. Journal of Counseling Psychology, 32, 221-231.

Robbins, S. B., Payne, C., \& Chartrand, J. M. (1990). Goal instability and later life adjustment. Psychology and Aging, 5, 447-450.

Robbins, S. B., \& Tucker, K. R., Jr. (1986). Relation of goal instability to self-directed and interactional career counseling workshops. Journal of Counseling Psychology, 33, 418-424.

Shrout, P. E., \& Fleiss, I. L. (1979). Intraclass correlations: Uses in assessing rater reliability. Psychological Bulletin, 86, 420-428.

Sim, J., \& Romney, D. (1990). The relationship between a circumplex model of interpersonal behaviors and personality disorders. Journal of Personality Disorders, 4, 329-341.

Watson, P., McKinney, J., Hawkins, C., \& Morris, R. (1988). Assertiveness and narcissism. Psychotherapy, 25, 125-131.

Weinstock-Savoy, D. (1986). The relationship of therapist and patient interpersonal styles to outcome in brief dynamic psychotherapy. Unpublished doctoral dissertation, Boston University.

Wiggins, J. (1979). A psychological taxonomy of trait-descriptive terms: The interpersonal domain. Journal of Personality and Social Psychology, 37, 395-412.

Wiggins, J., Trapnell, P., \& Phillips, N. (1988). Psychometric and geometric characteristics of the Revised Interpersonal Adjective Scales (IAS-R). Multivariate Behavioral Research, 23, 517-530.

Received April 23, 1991

Revision received May 5, 1992 Accepted May 6, 1992 